\title{
Informed Consent Process in the New Millennium
}

\author{
${ }^{1}$ Ranabir Pal, ${ }^{2}$ Swapan K Paul
}

\begin{abstract}
In this new millennium, the clinical trial is inseparably linked with an upgrade of health care by generating invaluable data in preventive, promotive and curative health. Globally research experts have concerns regarding ensuring financial and other compensations along with optimum health benefits for research participants in clinical trials in the emerging market economy. A significant number of human healthy volunteers (participants) take part in researches in both developed and developing countries. Participants are frequently unaware that the informed consent process is mandatory for investigators, funders and participants and their free will must be documented. There are sparse published medical works of literature that attempted to assess the extent to which all the norms of the informed consent process are followed in Indian settings in this area to the best of our knowledge. We need to conduct researches on the preparedness of the clinical trials participants towards their awareness of the criticality of the informed consent process and their motives for participation. This narrative review enlightened the facts that very patient, extensive and careful transparent narration and dissemination of the information can only ensure truly informed and autonomous decision improving the validity of the study.
\end{abstract}

Keywords: Clinical trials, Informed consent process, Participants.

How to cite this article: Pal R, Paul SK. Informed Consent Process in the New Millennium. Bengal Physician Journal 2018;5(2):22-24.

\section{Source of support: Nil}

Conflict of interest: None

\section{PROLOGUE}

Clinical research activities have seen impressive advancements globally and yet, monitoring instruments have been lagging behind this state of affairs in levels to share the benefits to the grassroots levels. This is true for both developing as well as developed countries. Most of the volunteers come from lower socio-economic strata stressing ethical issues of paramount importance. These subjects can easily be lured with an unexpected package

\footnotetext{
${ }^{1}$ Professor and Head, ${ }^{2}$ Assistant Professor

1,2Department of Community Medicine, Mata Gujri Memorial Medical College and LSK Hospital, Kishanganj, Bihar, India
}

Corresponding Author: Ranabir Pal, Professor and Head, Department of Community Medicine, Mata Gujri Memorial Medical College and LSK Hospital, Kishanganj, Bihar, India e-mail: ranabormon@yahoo.co.in of benefits to participating which often motivates these volunteers to participate frequently, sometimes simultaneously in multiple studies, neglecting the fact that participation in researches exposes them to the risk of serious, unpredictable harm owing to cumulative effect or interaction of various experimental interventions. ${ }^{1}$

Studies have explored the factors behind the motivations of research participants in developing countries. A healthier internalization of the core factors in the spectrum of altruism in one end to earning for bare minimum earthly needs on the other end allowed researchers to address these matters before commencing their investigation and informed consent process. ${ }^{2-4}$

Autonomy is accepted as the key aspect in the researches involving human participants, especially in the informed consent process as per International research ethics guidelines inclusive of disclosure of appropriate information, capacity for decision-making with voluntary approval without any form of coercion. ${ }^{5}$

Clinical trials are facing challenges of over-expectation, inadequate data, and funding, lack of interest of academic institutes. The recommendation is that clinical research expertise needs to be taught as the capacity building in an exciting way to stimulate interest in clinical research careers based on four basic pillars of human ethics as per Declaration of Helsinki. Institutional Ethics Committees (IECs) are expected to defend the rights, safety, and well-being of participants and in local and international health researches. ${ }^{6-8}$

Autonomy to leave the research project at any point of time without showing any reasons whatsoever and getting all types of information before participation are two major pillars of the informed consent process. While pseudo-coercion is the form of "narration-followed-bysignature" is the norm in developing countries including Indian settings should be stopped. The 'tunnel vision' of monetary and non-monetary gains often eclipse their mindset from serious, unpredictable harm owing to cumulative effect or interaction of various experimental therapies. Linguistic, cultural and many confounding community-level barriers add to their incompetence to follow informed consent process. High rates of illiteracy in parts of the world is a known barrier to understand research concepts and poor healthcare access both breeds nuisance and coercion of consent process. ${ }^{9-11}$

Therapeutic misconception is an ignored issue that may obscure the sanctity of the informed consent process 
by the inabilities of the participants to make a distinction between research process to find 'unknown truth' and standard clinical care based on time-tested interventions. Investigators and funders cannot bypass the responsibilities to educate the participants on this crucial issue. ${ }^{12-16}$

Indian Council of Medical Research (ICMR) ethical guidelines instructed investigators to obtain mandatory written informed consent conscientiously from before volunteering for medical researches on the human subject. ${ }^{17}$

Informed consent process implicates informing on the rights and responsibilities, potential risks and benefits, duration, etc., as with increasing understanding of clinical trials, there are higher chances of adherence to the study. Literature reports suggest that sometimes the volunteers may not be attentive in the process by overestimating benefit and overlooking drawbacks. ${ }^{15,18-20}$

Studies suggested that approach to the patient by the investigator/researcher and answering queries need to be streamlined at the level of understanding to administer a fully comprehensible consent form in a secluded setting in a comfortable atmosphere with adequate time for discussions and decision making. Research staffs must be trained in human research participant protection and show adequate respect as well as patience during inform consent process with the use of a checklist of the frequently asked questions providing adequate responses to them. Content and readability of form, the timing of discussion, amount of time allotted should be designed in is user-friendly manner. The informed consent form should be in the vernacular or a language the participant feel comfortable; individuals signing the consent form after being fully aware of what they are signing increases success of participation in a clinical trial in multilingual countries like India. Further, in illiterate participants, the researchers should have the patience to obtain informed consent by giving them space to discuss with their family and community members. ${ }^{21-25}$

Monetary benefits may increase participation, but that may be counterproductive in the long run. Instead in the developed countries, recent trend is to discourage undue participation by healthy volunteers to protect their health by a nationwide biometrics based 'volunteer data management system' to store retrospective participation history and help recruit prospectively of these registered users to check to ensure that particular volunteer group in the inclusion criteria is available for a particular study. $1,26,27$

\section{CONCLUSION}

In a multilingual and multicultural country like India, most volunteers come from lower socio-economic strata and usually get confused with the untested water of research which even educated citizen may be allured by the benefits. Thus, measures need to be put in proper place to discourage over-volunteering by healthy volunteers to protect their health with an overview of rigorous legal and ethical steps from the regulatory bodies and stakeholders of researches. Hence ethical issues are of utmost significance. By classifying the motivations to join a research project, researchers will identify a better approach for the informed consent process.

\section{REFERENCES}

1. Van Loon K, Lindegger G. Informed consent in clinical trials: Perceptions and experiences of a sample of South African researchers. Health SA Gesondheid (Online). 2009;14(1): 81-87.

2. Mansour H, Zaki N, Abdelhai R, Sabry N, Silverman H, El-Kamary SS. Investigating the informed consent process, therapeutic misconception and motivations of Egyptian research participants: a qualitative pilot study. Eastern Mediterranean Health Journal [Internet]. World Health Organization Regional Office for the Eastern Mediterranean (WHO/ EMRO); 2015 Mar 1;21(3):155-163.

3. Aitken L, Gallagher R, Madronio C. Principles of recruitment and retention in clinical trials. Int J Nurs Pract. 2003;9(6):338346.

4. Ballantyne A. Benefits to research subjects in international trials: do they reduce exploitation or increase undue inducement? Dev World Bioeth. 2008;8(3):178-191.

5. Sreenivasan G. Does informed consent to research require comprehension? Lancet. 2003;362(9400):2016-2018.

6. Shweta K, Vidhi D, Satyaendra S. An overview of challenges and dire need of clinical trials. Calicut Med J 2007;5(3):e2.

7. Normile D. The promise and pitfalls of clinical trials overseas. Science 2008;322(5899):214-216

8. Hellard ME, Sinclair MI, Forbes AB, Fairley CK. Methods used to maintain a high level of participant involvement in a clinical trial. J Epidemiol Community Health 2001; 5(5):348-351.

9. Khalil SS, Silverman HJ, Raafat M, El-Kamary S, El-Setouhy M. Attitudes, understanding, and concerns regarding medical research amongst Egyptians: a qualitative pilot study. BMC Med Ethics. 2007;8:9.

10. Mudur G. Indian study of women with cervical lesions called unethical. Br Med J 1997;314(7087):1065.

11. Bandewar S. Cultural barriers, 'competence' and informed consent in population-based surveys. Indian J Med Ethics 2003;11:2.

12. Appelbaum PS, Roth LH, Lidz C. The therapeutic misconception: informed consent in psychiatric research. Int J Law Psychiatry. 1982; 5(3-4):319-29.

13. Appelbaum PS, Lidz CW, Grisso T. Therapeutic misconception in clinical research: frequency and risk factors. IRB. 2004;26(2):1-8.

14. Cassileth BR, Zupkis RV, Sutton-Smith K, March V. Informed consent - why are its goals imperfectly realized? N Engl J Med. 1980;302(16):896-900.

15. Lynöe N, Sandlund M, Dahlqvist G, Jacobsson L. Informed consent: study of quality of information given to participants in a clinical trial. BMJ. 1991; 303(6803):610-613. 
16. Al-Amad S, Awad M, Silverman H. Attitudes of dental patients towards participation in research. East Mediterr Health J. 2014; 20(2):90-98.

17. Brahme R, Mehendale S. Profile and role of the members of ethics committees in hospitals and research organisations in Pune, India.Indian J Med Ethics. 2009;6:78-84.

18. Comis RL, Miller JD, Aldigé CR, Krebs L, Stoval E. Public attitudes toward participation in cancer clinical trials. J Clin Oncol. 2003; 21(5):830-835.

19. Wallington SF, Luta G, Noone AM, Caicedo L, Lopez-Class $\mathrm{M}$, Sheppard V, et al. Assessing the awareness of and willingness to participate in cancer clinical trials among immigrant Latinos. J Community Health. 2012; 37(2):335-343.

20. Lackey DP. Critical Research in developing countries recent moral arguments. Cad Saude Publica 2002;18(5):14551461

21. Woodsong C, Abdool Karim Q. A model designed to enhance informed consent: Experiences from the HIV prevention trials network. Am J Public Health 2005; 95(3):412-419.
22. Sastry J, Pisal H, Sutar S, Kapadia-Kundu N, Joshi A, Suryavanshi $\mathrm{N}$ et al. Optimizing the HIV/AIDS informed consent process in India. BMC Medicine 2004;2:28.

23. Taylor HA. Barriers to informed consent. Semin Oncol Nurs 1999;15(2):89-95.

24. Beardsley E, Jefford M, Mileshkin L. Longer consent forms for clinical trials compromise patient understanding: so why are they lengthening? J Clin Oncol 2007;25:e13-e14.

25. Emanuel EJ, Wendler D, Grady C. What makes clinical research ethical?. Jama. 2000 May 24;283(20):2701-2711.

26. Guidelines for phase I clinical trial. The Association of the British Pharmaceuticals Industry. 2012 edition. [online] Available at https://www.abpi.org.uk/media/1627/guidelines_phase1_clinical_trials.pdf.

27. Joseph P, Schackman BR, Horwitz R, Nerette S, Verdier RI, Dorsainvil $\mathrm{D}$, et al. The use of an educational video during informed consent in an HIV clinical trial in Haiti. JAIDS Journal of Acquired Immune Deficiency Syndromes. 2006 Aug 15;42(5):588-591. 